\title{
How to Refute Inaccurate Media and Government Reports on Medicine: What Can One Doctor Do?
}

\author{
James I. AUSMAn, ${ }^{1}$ Tadashi SHIBUYA, ${ }^{2}$ Kazuhiro HONGO, ${ }^{3}$ \\ Nobutaka KAWAHARA, ${ }^{4}$ and Toshihiko WAKABAYASHI ${ }^{5}$ \\ ${ }^{1}$ Department of Neurosurgery, David Geffen School of Medicine, UCLA, \\ Los Angeles, California, USA; \\ ${ }^{2}$ Department of Neurological Surgery, Nihon University School of Medicine, Tokyo; \\ ${ }^{3}$ Department of Neurosurgery, Shinshu University School of Medicine, Matsumoto, Nagano; \\ ${ }^{4}$ Department of Neurosurgery, Graduate School of Medicine, \\ Yokohama City University, Yokohama, Kanagawa; \\ ${ }^{5}$ Department of Neurosurgery, Graduate School of Medicine, Nagoya University, Nagoya, Aichi
}

\section{Introduction}

The first author (JIA) was asked by the Japan Neurosurgical Society (JNS) and Professors Kayama and Katayama to present his views on "How to Refute Inaccurate Media and Government Reports on Medicine" for the Japanese neurosurgeons. This report could not have been done without the contributions of the other authors: Professors Shibuya, Hongo, Kawahara, and Wakabayashi, whose valuable comments and insight contributed greatly to this paper.

\section{The Problem}

In recent publication in The Japan Times ${ }^{1)}$ there was a report of a gynecologist who performed a Caesarean section on a pregnant woman, who had a retained placenta. The patient subsequently had a severe episode of bleeding which led to her death. Questions were raised about whether the patient should have been transferred to another facility. The doctor was arrested by the police and charged with professional negligence. Eventually, the charges were dropped.

A second report in The Japan Times ${ }^{2}$ stated that an emergency room (ER) physician treated a 4-year old child who had fallen on a chopstick that penetrated his throat and also his brain. On examination the physician found the throat penetration, which he treated but the brain puncture was not obvious on his examination. Within 24 hours the child died of a brain hemorrhage. The family sued the doctor for negligence, but the court dismissed the charges $2^{1 / 2}$ years later. ${ }^{3)}$

\section{The Results}

The Japanese physicians were very concerned about this exposure in the media. They believed that this public reporting of medical problems affecting their patients could damage their reputations even though eventually the doctors were found not guilty of the charges made. This public embarrassment made it difficult for these doctors to practice and for patients to come and see them. It is very hard to recover from this type of public criticism. As a result, ER physicians became reluctant to treat patients, and doctors did not want to take difficult cases because of fear of being arrested or sued and of public exposure in the media. Some doctors even criticized other doctors placing the blame on them to protect themselves from criticism. This practice is not good as it places doctors against one another instead of cooperating.

The government recognized the bad results of this reporting against the doctors and supported an informed consent practice among doctors to help protect them. And an informed consent would provide a record that the doctor had told the patient of the dangers during treatment. In Japan, more lawyers are taking malpractice cases, and the problem continues to grow for doctors.

\section{What is Happening Elsewhere?}

This problem of growing malpractice cases is occurring worldwide in countries that never had the problem before. In the United States, the media is usually not involved in malpractice cases, but it is happening more. The newspapers will write about doctors who are charging too much, making profit 
from companies they own whose products they personally use, ${ }^{4)}$ or who are found doing unnecessary spine surgery, ${ }^{5)}$ as an example. The other malpractice problems faced by the neurosurgeons in the United States are the same as those in Japan. ${ }^{6}$ Forty-one percent of Massachusetts's physicians have altered or limited their practice for fear of being sued. ${ }^{6}$ Most liability claims or malpractice cases against doctors are without merit. In 2011, $65 \%$ of the claims against physicians were dropped, withdrawn, or dismissed. Of the remaining 35\% of the cases, less than $10 \%$ were decided by trial. Of those that went to trial, the physician defendant in the case won $90 \%{ }^{6)}$

\section{Personal Experience of First Author}

In my own experience in 50 years as a neurosurgeon, I treated high-risk patients that no one else wanted to treat. I did establish a close friendship with the patients and their families. They understood the seriousness of the problem but wanted hope. We were not always successful, but the patients and their families were grateful. Still, I have been sued 5 times in that period. None were successful. Two suits were by physicians. One had lost his vision in one eye from a meningioma that he treated himself with steroids. He was referred to me by another neurosurgeon, who did not want to do the case as the patient was losing vision in his only remaining seeing eye. The patient was again treating himself with steroids. I operated to save his vision, but he lost the vision in the remaining eye and became blind.

The problem in the case was that I was a white doctor operating on a black patient in a city with racial conflict of black against white. The lawyer for the patient was a prominent black attorney, who wanted to make the case a racial issue. I was personally very upset about this circumstance as I could see my career being destroyed by a racial trial, not one based on fact. I could see intense media exposure of this case to my detriment. Everything my parents had sacrificed for me to become a physician and I had worked for was in jeopardy. Fortunately, Dr. Thor Sundt, a highly respected neurosurgeon in the United States at the time, rose to my defense. The case was settled out of court. I did nothing that was malpractice. I had a second case again with a black physician in another racially divided city. It went to trial and the doctor-patient lost. Both of these experiences of mine occurred in states that had the highest number malpractice suits in the country. So, I have experienced the same concerns as the
Japanese physicians.

The average neurosurgeon in the United States is sued about once in 10 years. $\left.{ }^{6}\right)$ I have given expert testimony in many cases, mostly for the doctors but sometimes for the patient, if I believe that the doctor was extremely wrong in what he did. As head of two departments of neurosurgery with 15 neurosurgeons over 25 years, there was never a successful suit brought against any of us.

In one case, I operated a patient to remove a posterior fossa hemangioblastoma, which another surgeon failed to remove. The patient did well after surgery but went down to get a computed tomography (CT) scan 3 weeks after surgery. The patient had a ventricular drain in place. The radiology technician injected dye into the ventricular catheter instead of injecting into a vein. The patient immediately developed seizures and died. We went to the patient's husband, with whom we had a good relationship, and admitted our mistake. Within one week the case was settled by the hospital in a fair way.

\section{Collaborative Care}

Why did we have such a small number of suits for a neurosurgical department? Even lawyers did not want to sue us because they knew they would lose the case. For 25 years all the members of the department met every afternoon and reviewed all the cases on the service. We discussed each case for surgery the next day and the problems the surgeon should consider. We gave advice to each other. We also had a television system that connected my office to each operating room and other parts of the hospital, so that we all could discuss each case as it was progressing, no matter where we were in the hospital. In addition, the residents could see more cases on the television system regardless where they were. So, the system had educational value.

Every surgeon, including me, always had the opportunity for our colleagues to give us advice during the case. We also made rounds in the morning together with the nurses, nurse practitioners, residents, social workers, pharmacist $\mathrm{PhD}$, discharge planner, and even psychiatrists, and any visiting physicians. We were open to all suggestions to get the best care for the patient. Our discussions were all documented in the patient's chart and discussed with the patient by the nurse practitioners. I called this system Collaborative Care. That type of care assured the best for every patient and resulted in a low number of malpractice suits, high quality care, and low complications. Even lawyers did not want to sue us because they knew they would not find any 
negligence. We could establish that we had done the best we could do with many opinions being heard. I suggest that you should consider establishing a Collaborative Care system in your hospital.

\section{What Can One Doctor Do to Prevent Malpractice Suits and the Media Exposure?}

There are fundamental principles of medicine that any physician should always understand.

1. Rule \#1: THE PATIENT COMES FIRST. This rule is broken many times by doctors, nurses, hospital administrators, insurance companies, and government systems. Patients come to the doctor and trust the doctor with their life. They expect that the doctor will watch over their life 24 hours a day and 7 days a week for as long as they are their patient. Do doctors fulfill this unwritten contract between the patient and doctor? Do nurses or members of the hospital administration do this? Or do the insurance companies or government systems fulfill this pledge? The answer is NO.

2. Rule \#2: TREAT THE PATIENT AS IF HE/SHE IS A MEMBER OF YOUR FAMILY. It does not matter what any study shows. The real decision to make is what you would do in the same situation as the patient if he or she were your father, mother, brother, or sister. If you make all your decisions with that basic principle, you will never make a mistake.

3. Rule \#3: CHOOSE THE TREATMENT WITH THE LOWEST RISK AND THE BEST OUTCOME FOR THE PATIENT. The word surgery does not appear in that rule. If I am in an operation and encounter a set of circumstances that are more complex than I expected or discussed with the patient, I will stop the operation, close, allow the patient to wake from surgery, so that the patient may have the choice to do what they want with their life. That is not my decision. I have even brought patients' families to the operating room to show them the problem and to ask their opinion about what to do if the patient is not able to do so. It is not my life; it is the patient who is taking all the risks. They have the right to decide what is done with their life.

4. Rule \#4: TALK WITH THE PATIENTS; BECOME A FRIEND TO THE PATIENT. TELL THEM THE TRUTH. GIVE THEM HOPE. EVERYONE WANTS HOPE. Or at least try as hard as you can to help them. One patient told me, "I know that you cannot cure me, but I know that you care."

5. Rule \#5: TELL THE PATIENTS WHAT YOU KNOW AND WHAT YOU DO NOT KNOW. They do not expect you to know everything. Tell them about someone who knows better than you do how to treat the problem. That practice places the patient first instead of the doctor. That is what you would want your doctor to tell you if you were a patient. Give them the chance to go to another doctor if they want. They will trust you more for saying this. Remember you are hired by the patient to be their consultant, to help explain to them the complex field of medicine, and to help them understand their problem so that they can make a decision on their own life. You are not a God. You ask for advice from other physicians who know more than you do in other specialties. So, why not talk about what you do not know to the patient?

6. Rule \#6: REFER THE PATIENT TO THE BEST PERSON YOU KNOW. I remember practicing in a city in the United States. We had a neurosurgeon in our staff who was an expert in treating arteriovenous malformations. But a doctor in the community told the patient that there was no doctor in town who could do the case and referred the patient elsewhere. The patient did come to see us and was treated. The community doctor was embarrassed to admit that someone in the community knew more about the problem then he did. The patient in that situation came last and the doctor's interest came first. That violated Rule \#1. Also, some hospital administrators do not want to transfer patients from their hospital to other hospitals because it will mean a loss of revenue or an empty bed. That places the patient last and the administration and hospital first above the patient. That decision also violates Rule \#1.

7. RULE \#7: IF YOU MAKE A MISTAKE, ADMIT IT. Many lawyers will tell you not to do this. But that is not how we are raised as physicians. We must always know and tell the truth. If we do not say what is true, we cannot practice Medicine, because the facts we will use will be wrong. If someone else wants to cover up the truth, that is fine for them but not for you as a physician. That is what you would expect as a patient and what the public expects. So, why do any differently? Rule \#1: The patient comes first.

\section{The Other Side of the Story}

In a publication "Public Citizens Congress Watch-2005" 
in the United States ${ }^{7)}$ the malpractice suits were reviewed from 1991 to 2004 . What the study showed was that the verdicts by juries in malpractice suits against physicians had not changed in the amounts paid over that 13-year period when adjusted for inflation. Second, the same study showed that the payments were the highest for the cases that had the most severe outcomes. That is reasonable. It happens that neurosurgeons are involved in cases that can produce very serious outcomes. That is our profession. Again in the same study ${ }^{7}$ it was shown that in some states in the United States the malpractice premiums paid by doctors over a four-year period went up $2 \mathrm{X}$ or $3 \mathrm{X}$. There was no good reason for this rise except that the insurance companies were protecting themselves from threatened lawsuits. So, in one state one-third of the neurosurgeons left the state and moved to other states, where the malpractice charges were lower. ${ }^{7)}$ That migration of doctors results in the patients losing doctors who could care for them. Nothing was done by any national medical society to stop this practice. The patients suffered as a result. Rule \#1 was broken.

The conclusions from the "Public Citizens Congress Watch-2005" were that (1) the evidence showed that lawsuits did not cause the rise in insurance premiums for doctors. (2) The total value of malpractice payouts had not increased over 13 years. (3) There was a $56 \%$ decline in multimillion-dollar payouts over that period of time. ${ }^{7)}$

Yet, the study showed that $5.5 \%$ of doctors were responsible for $57 \%$ of malpractice payouts, usually because of a failure to diagnose the problem or because of improper performance. Doctors with repeated malpractice payouts suffer few consequences. Their state medical board disciplined only $8.3 \%$ of doctors, who had two or more malpractice suits. Only $11.4 \%$ of doctors with three or more malpractice suits were disciplined by their state board. Only $14.6 \%$ of doctors with four or more malpractice suits were disciplined. The obvious conclusion is that DOCTORS NEED TO DISCIPLINE THEMSELVES BETTER. Lawyers, politicians, and administrators will all tell the same conclusion. But doctors are reluctant to discipline their colleagues. ${ }^{7)}$ So, Rule \#1 is broken again: The patient does not come first, the doctor does, which is wrong.

\section{So, How Can One Doctor Stop Inaccurate Media Stories?}

There are two answers to this question. One is that each doctor should follow the principles above including participating in a collaborative care system and be the best doctor that they can be with each patient.

One doctor cannot stop all of this bad Press, alone. So, doctors need help. The second answer is that the local and national neurosurgical societies can help with this problem. The national societies have POWER because they represent all the neurosurgeons. But they need the neurosurgeons to be behind them and to advocate what is best for the patient and to speak the facts and the truth.

In the United States, the American Medical Association and the American College of Surgeons, two large medical organizations, negotiated with the US government about socialized medicine proposed by the Obama administration. In the political world, the government promised these societies that certain things would be done in exchange for their support. After the legislation was passed with the support of these societies, the politicians withdrew their promise to the societies and in effect, lied to the societies. Both major neurosurgical societies in the United States did not agree to vote for the government plan. They did the right thing. That is what the neurosurgeons wanted done. The other societies abandoned the patient for political gain. Rule \#1 was broken by major medical organizations.

But, as in all organizations, there are good and bad parts of the organization. Some leaders of the societies want POWER and want to serve their own personal interests. Also, the societies often choose "safe solutions" to problems rather than confronting them, which has more risk but in most cases is the right thing to do. Again, no one wants to take the blame for controversial decisions being made.

Doctors must realize that they are uninformed and inexperienced in the ways of politics. The politicians are experts at politics. Politicians use the Press to convince people of their positions, even positions against physicians. Governments and politicians want to control the people for POWER and to control the money for healthcare and, thus, control the public. The leaders of the national societies must be willing to negotiate strongly, but they rarely do this because of their inexperience in politics. The politicians use the Press to embarrass the doctors into agreeing with the political positions. Thus, national organizations need help from others including political legal consultants in dealing with complex political and social situations. 


\section{A Simple Rule of Negotiation}

There is a simple rule of negotiation to remember: IF YOU GIVE SOMETHING UP, YOU MUST RECEIVE SOMETHING OF EQUAL VALUE IN RETURN. There is an excellent book on "You can negotiate anything" by Herb Cohen. I have recommended it for years in my lectures to neurosurgeons. It can be purchased on Amazon.

\section{What Have the Brazilian Neurosurgeons Done to Work with the Government?}

In Brazil, in the past, anyone who finished medical school could say that they were a neurosurgeon, without any training. So Brazil had 2,000 neurosurgeons of varying quality. There were no standards of education. And the neurosurgeons were paid a low amount for their care. So, the neurosurgeons united under the active guidance of Carlos De Sousa, who personally visited all of the neurosurgeons in Brazil. With their support they formed a plan to present to the government.

The Brazilian Society of Neurosurgeons (BNS) proposed that the government should restrict those who were neurosurgeons by developing a certification system administered by the neurosurgical society with examinations. That would eliminate those who were poorly trained. There were too many procedures being done in many hospitals that were not equipped for these cases. So the BNS proposed that in hospitals with three or less neurosurgeons only certain types of cases could be done. In those with more than three neurosurgeons, more complicated cases could be done. And in those hospitals with a large number of neurosurgeons, a number was specified by the BNS, all the procedures could be done. This proposal was best for the patients and saved the government's money. Patients were also staying in hospitals too long. So the BNS proposed that they would reduce the length of stay by one week for neurosurgical cases if the government would pass that cost savings on to the neurosurgeons as increased pay. They used the rule of negotiation explained above. The government accepted their proposal. So, a constructive solution was found that solved the government's problems and the neurosurgeons' problems. Quality of care improved.

\section{What the Japan Neurosurgical Society (JNS) Can Do}

The JNS can propose a plan to help the government solve the healthcare problems of the country. This would be a pro-active position, before the govern- ment and politicians took a position that the society would not like. Solving the malpractice problem would be one issue for the neurosurgeons. For the government, the public wants to have quality of care at a reasonable cost. The JNS can hire lawyers and politicians to advise the society on how to negotiate with the politicians and the government. You must realize that this is not a scientific discussion. It is a fight for POWER, because politicians are concerned with POWER. Yes, everyone will say it is to help the public, but it is usually POWER that is the motive and what is in the result for the negotiating parties. Thus, the JNS needs advice on how to manage these negotiations in a fair way.

As a possible solution, a Malpractice Board can be formed by the JNS, composed of senior neurosurgeons. Japan has many experienced and influential senior neurosurgeons who have retired and who would be happy to participate in this Malpractice Board. There should be a citizen member of the Board. The members of the Board would be changed regularly to prevent any bias from occurring. This Board could render an objective opinion in every malpractice case and make recommendations. The recommendation may or may not be held as final by the courts, but probably would be. From their determinations this Malpractice Board can also recommend corrective action for the neurosurgeon involved, if necessary, and propose a plan of discipline for those according to the judged offence. As a result the public will be pleased, and the Press will be silenced.

Then the JNS can agree to work with the government to solve other problems that both the government has and that the neurosurgeons face. It is hard to find malpractice cases discussed in the literature. Surgical Neurology International presents a number of malpractice cases particularly in its spine supplement. It is hard to find advice in this area, but this is one option. In the journal of the JNS, these issues could also be discussed.

\section{The Role of Senior Neurosurgeons in These Negotiations}

In Japan, it is my belief that neurosurgeons are asked to retire from official positions at the age of 65 , which is too low an age for retirement. These neurosurgeons then go on to administrative positions in large or small hospitals, and their great talent and experience is lost to Japan and the world. I believe that that retirement age should be raised. People are living into their 80 s in Japan. ${ }^{8)}$

Also these senior neurosurgeons have established excellent connections with important people through 
their work, which makes them highly qualified to speak for the JNS. Most have had positions in the JNS. These senior neurosurgeons should be used by the JNS to conduct these high level relationships with the government. They should also be rotated in their positions. Other activities can be found for those who do not want to continue their neurosurgical work. They can help younger neurosurgeons manage departments, so that they can be more successful. There are many constructive activities that they can do. This example will also provide a guide to the rest of Japanese society on how its senior citizens can be useful throughout their lives. It will help solve a very serious problem of what to do with an aging society. Everyone wins with this idea.

\section{Another Suggestion for the Neurosurgeons of Japan}

In my years of many visits to Japan I have always been impressed with the high level of neurosurgery in Japan led by excellent neurosurgeons and leaders. I have read your journal every month for years. Japanese neurosurgery does outstanding world-leading research in many areas and has many accomplished neurosurgeons, who have made major contributions to world neurosurgery. Yet, from my perspective, world neurosurgery has not given the Japanese neurosurgeons the continuing recognition they deserve. Some reasons are related to the distance of Japan from other countries with developed neurosurgery. Others include the lack of recognition of the accomplishments of the younger neurosurgeons internationally. Some are related to bias of the surgeons in a particular area of the world and their limited perspective on what is being done in world neurosurgery. Also, the Japanese neurosurgeons are isolated on an island, and their contact with other continents is not as easy as in Europe and the United States or even South America. I have made some personal suggestions to President Kayama of the JNS for ways to solve this issue.

I will be happy to help in any way I can and open the pages of Surgical Neurology International to the Japanese neurosurgeons to show their work, lectures, and excellent surgery all for free so that the rest of the world can see the great accomplishments and work of the Japanese neurosurgeons.

I am most grateful to have had the opportunity to learn from many Japanese teachers, to have many as friends for a long time, and to have the chance to come to your meetings.

\section{References}

1) Doctor held over botched Caesarean. The Japan Times, Feb 19, 2006. http://www.japantimes.co.jp/ news/2006/02/19/national/doctor-held-over-botchedcaesarean/\#.UqP46JGIe48

2) Doctor faces year over child's death. The Japan Times, Nov 15, 2005. http://www.japantimes.co.jp/ news/2005/11/15/national/doctor-faces-year-overchilds-death/\#.UqP4AZGIe48

3) Hospital, doctor cleared in chopstick suit. The Japan Times, Feb 13, 2008. http://www.japantimes.co.jp/ news/2008/02/13/national/hospital-doctor-clearedin-chopstick-suit/\#.UqP4g5GIe48 (Brain Injury)

4) Whoriskey P: Rise in spinal fusion surgeries may be driven partly by financial incentives, study says. Washington Post. Nov 13, 2013. http://www.washingtonpost.com/business/economy/rise-in-spinalfusion-surgeries-may-be-driven-partly-by-financialincentives-study-says/2013/11/13/2c87188a-4c8711e3-be6b-d3d28122e6d4_story.html

5) Whoriskey P, Keating D: Spinal fusions serve as case study for debate over when certain surgeries are necessary. Washington Post, Oct 27, 2013. http:// www.washingtonpost.com/business/economy/spinalfusions-serve-as-case-study-for-debate-over-whencertain-surgeries-are-necessary/2013/10/27/5f015efa25ff-11e3-b3e9-d97fb087acd6_story.html

6) Medical Liability Reform Now! AMA Publications. http://www.ama-assn.org/resources/doc/arc/mlr-now. pdf

7) Medical Malpractice: Payout Trends 1991-2004. Public Citizens Congress Watch 2005. http://www.citizen. org/documents/Malpracticeanalysis_final.pdf

8) Wikipedia. List of Countries by life expectancy. http:// en.wikipedia.org/wiki/List_of_countries_by_life_ expectancy

Address reprint requests to: James I. Ausman, MD, $\mathrm{PhD}$, 70950 Fairway Drive; Rancho Mirage, California 92270, USA.

e-mail: jamesausman@mac.com 